\title{
Student Pharmacists' Emotional Responses and Coping During the COVID-19 Pandemic
}

\author{
Hannah E. Johnson, PharmD ${ }^{1 *}$, DeAundre Bumpass, PharmD ${ }^{2}$, Aric Schadler, PhD ${ }^{1,3}$, Jeff Cain, EdD, MS ${ }^{1}$
}

\begin{abstract}
Introduction: Health professions students, including student pharmacists, have been impacted by the coronavirus disease 19 (COVID-19 pandemic) as schools have transitioned to remote learning and cancelled milestone events. During times of crises, media consumption and hobby participation also impact well-being. The adverse emotional responses and coping strategies of student pharmacists amidst the COVID-19 pandemic have not been evaluated, nor have factors that may contribute to emotional responses. The purpose of this study is to determine Doctor of Pharmacy students' emotional responses and coping precipitated by the COVID-19 pandemic, and the influence of media use, working status, and participation in hobbies.
\end{abstract}

Methods: An anonymous online survey was administered to student pharmacists from May 21 to June 7 , 2020 at one school of pharmacy in Kentucky. Measures included gender, working status, media source and use, hobby participation, emotional responses, and the Brief COPE to measure coping reactions.

Results: A total of 550 student pharmacists from the University of Kentucky College of Pharmacy were invited to participate the study. Seventy-seven participants completed the survey, identifying feelings of anxiety, fear, sadness, and anger related to the COVID-19 pandemic. Participants who consumed less than one hour of media per day were significantly less likely to feel fear than those who consumed one to three hours ( $\mathrm{p}=$ 0.043). The primary news source for participants, as determined by the survey, was social media, including Twitter ${ }^{\oplus}$, Instagram ${ }^{\circledast}$, and Facebook ${ }^{\oplus}$. Students who continued to work during the pandemic reported less fear $(\mathrm{p}=0.020)$ and sadness $(\mathrm{p}=0.025)$ compared to those who did not. Those who participated in hobbies were also significantly less likely to report feelings of sadness $(p=0.001)$. Student pharmacists reported using approach coping more frequently than avoidant.

Conclusion: Life-disorienting events, like the COVID-19 pandemic, can negatively affect student pharmacists' well-being. Pharmacy schools should prepare student pharmacists for times of both major and minor crises.
DOI: 10.18297/jwellness/vol3/ iss $3 / 3$

Received Date: Aug 9, 2021 Accepted Date: Nov 13, 2021 Publication Date: Dec 16, 2021 Website: https://ir.library.louisville.edu/jwellness/

Recommended Citation: Johnson, Hannah E.; Bumpass, DeAundre; Schadler, Aric; and Cain, Jeff (2021) "Student Pharmacists' Emotional Responses and Coping During the COVID-19," Journal of Wellness: Vol. 3: Iss. 3, Article 3.

Affiliations: ${ }^{1}$ Department of Pharmacy Practice and Science, College of Pharmacy, University of Kentucky, ${ }^{2}$ Walgreens Pharmacy, ${ }^{3}$ Kentucky Children's Hospital

\section{INTRODUCTION}

The coronavirus disease 19 (COVID-19), caused by severe acute respiratory syndrome coronavirus 2 (SARS-CoV-2), has had a significant effect on global public health [1]. On March 11, 2020; the World Health Organization (WHO) declared the COVID-19 pandemic; state-mandated social distancing and quarantine orders were placed to decrease spread of disease $[1,2]$. These containment measures have shown detrimental impacts on mental health, especially in young adults, ages 18-24 years old [3]. High-risk groups, such as individuals directly or indirectly in contact with the virus, people vulnerable to mental health problems, and health professionals' mental well-being have also been threatened [1]. Health professions students, including medical students, nursing students, and student pharmacists have been uniquely impacted by the COVID-19 pandemic, placing them at increased risk for COVID-19-related stress. Schools quickly transitioned to remote learning and canceled milestone events, yet health professions students remained front-line workers completing experiential rotations, volunteering with the public in a variety of areas, and many carrying part-time jobs outside of their coursework: dedicating time at hospitals, clinics, retail pharmacies, and SARS-CoV-2 testing/vaccination sites [4, 5-9].

Information can play an important role in how people respond to stressful events. During times of crises, media serves as a source of information and directly impacts the viewer's behavior, both positively and negatively [10]. Media, including print, radio, television, and the internet are rampant tools for people to seek information. Social media also plays an important role in modern life and has provided health-related information and connectivity during the COVID-19 pandemic [11]. However, the quickly evolving pandemic, high contagion risk, and lethality of SARS-CoV-2 has led to misinformation and exaggerations of COVID-related news [12]. Psychological 
distress, including anxiety, depression, and posttraumatic stress disorder have been found to correlate with COVID-19 disinformation exposure [13]. Conversely, participation in hobbies and other leisure activities has been shown to enhance both physical and psychological well-being [14]. Staying physically active may offer some protection from negative emotional responses, such as loneliness and depression, especially during times of stress [15].

In response to the concern for the well-being of health professionals and young adults during the COVID-19 pandemic, colleges and schools need to understand not only student stressors, but how students cope and respond. To cope is the effort to reduce distress, threat, harm, and loss in times of adversity or stress [16]. Stressors can include life-threatening illness and natural disasters [17]. Prior to the pandemic, student pharmacists already cite multiple sources of stress, therefore ensuring well-being is maintained during times of crises is of utmost importance [18]. This information will allow educators to advise, counsel, and teach students during periods of elevated stress. The purpose of this pilot study is to identify Doctor of Pharmacy (PharmD) students' adverse emotional responses and coping during the COVID-19 pandemic. Secondarily, the study assesses how media consumption, working status, and hobby participation might influence emotional responses to stress. The researchers hypothesized that strong negative emotional responses were elicited by the COVID-19 pandemic, specifically in those who consumed more time on social media, continued to work, and who did not participate in hobbies.

\section{METHODS}

\section{Participants}

Approximately 550 Doctor of Pharmacy students enrolled at the University of Kentucky College of Pharmacy (a public, fouryear program) were invited to participate in a study to assess emotional responses and coping strategies during the COVID19 pandemic on May 21, 2020. Currently enrolled students were contacted through the University of Kentucky College of Pharmacy e-mail listservs. Interested students could click on the survey link in the email and voluntarily consent to participate.

\section{Procedures}

Students who elected to participate completed an anonymous online survey administered via Qualtrics (Provo, UT). Students were able to refuse to take part in the research or exit the survey at any time without penalty. A reminder was sent on May 25, 2020 and the survey closed on June 7, 2020. The study was deemed exempt by the University of Kentucky Institutional Review Board.

\section{Measures}

The 47-question survey (available upon request to the author) developed by the investigators collected demographic data, such as gender, race, ethnicity, birth year, marital status, graduation year, and working status during the pandemic. Work status at the start of the pandemic, as well as changes in work status (being laid off, furloughed, or migration / modifications in job responsibilities) during the pandemic were evaluated. Sources of news, time spent consuming media coverage, and participation in hobbies were collected to assess the impact these may have on emotional responses.

The Emotional Responses Scale, developed by Huang et al, was used to measure negative emotional responses to the COVID-19 pandemic, including feelings of anxiety, fear, sadness, and anger. These measures were rated by participants on a 5-point Likert scale ranging from 1 (strongly disagree) to 5 (strongly agree), with 3 (neither agree nor disagree) representing a neutral value [4]. Item ratings were averaged to create a single index. Average scores higher than 3 implied that participants agreed with the statement and average scores below 3 implied that they disagreed with the statement. The farther the average was from neutral, the stronger the group's feelings.

The Brief COPE (a validated 28-item scale that evaluates 14 different coping reactions) was used to measure coping strategies $[4,17,19]$. These coping reactions were categorized into two subscales: approach or avoidant coping. Approach coping refers to efforts to solve or manage a stressful situation by acting and / or changing the perception of the situation. Examples of approach coping include active coping, seeking emotional support, using informational support, positive reframing, planning, and acceptance. Avoidant coping involves efforts to make a person feel more comfortable during stressful situations but does not work to counteract or mitigate the stressor itself. Examples of avoidant coping include self-distraction, denial, substance use, behavioral disengagement, venting, and selfblame [20]. Religion and humor were also evaluated by the Brief COPE, but do not fall under approach or avoidant coping. The participants rated the level of use of each coping reaction using a 4-point Likert scale from 1 (I haven't been doing this at all) to 4 (I've been doing this a lot). Each reaction was assessed twice with higher scores indicating greater use of the coping strategy by participants (maximum score $=8$ ). The score for each coping subscale (approach and avoidant) was calculated by adding the total score for each reaction within its respective subscale.

\section{Statistical Analyses}

Descriptive statistics were used for demographic characteristics. Independent samples t-test, Pearson's chi-square, and an ANOVA with a post hoc Bonferroni pairwise comparison was used as appropriate to evaluate the relationship between demographic data, work status, media use, and hobby participation and participants' emotional responses and coping strategies. Statistical analysis was completed using SPSS version 27 (SPSS Inc., Chicago, IL). An alpha level $<0.05$ was used to assess statistical significance.

\section{RESULTS}

A total of 550 requests were sent and 77 valid questionnaires were completed ( $14 \%$ response rate). The demographic characteristics of the cohort are presented in Table 1 . The majority of respondents identified as female (80.5\%), single (83.1\%), 25 years of age or younger $(75.3 \%)$, and were employed at the start of the pandemic (85.7\%). Half of employed students reported being laid off or furloughed from their job during the pandemic and $18 \%$ reported changes in job responsibilities. One-third 
of participants reported providing care to an individual with known or suspected SARS-CoV-2 infection. The primary news source for participants was social media, including Twitter ${ }^{\circledast}$, Instagram $^{\circledast}$, and Facebook ${ }^{\circledast}$. Students reported varying amounts of time spent consuming these media sources. Two-thirds $(\mathrm{N}=51$, $66.2 \%$ ) of participants reported inability to participate in a usual hobby due to mandated closures during the pandemic. However, most $(69,89.6 \%)$ reported starting a new hobby or picking up an old hobby during that time. The most common were games, sports, outdoor activities, and food and cooking-related hobbies.

Table 1: Demographics of Student Pharmacists Who Participated in a Survey to Determine Their Feeling and Coping Strategies During the COVID-19 Pandemic $(\mathrm{N}=77)$

\begin{tabular}{|c|c|}
\hline VARIABLE & NO. (\%) \\
\hline \multicolumn{2}{|l|}{ Gender } \\
\hline Female & $62(80.5)$ \\
\hline \multicolumn{2}{|l|}{ Race/Ethnicity } \\
\hline White & $66(85.7)$ \\
\hline Black & $5(6.4)$ \\
\hline Asian & $4(5.2)$ \\
\hline Hispanic & $2(2.6)$ \\
\hline American Indian & $1(1.3)$ \\
\hline Other & $2(2.6)$ \\
\hline \multicolumn{2}{|l|}{ Graduation Year } \\
\hline 2020 & $8(10.4)$ \\
\hline 2021 & $42(54.5)$ \\
\hline 2022 & $16(20.8)$ \\
\hline 2023 & $11(14.3)$ \\
\hline \multicolumn{2}{|l|}{ Age } \\
\hline $18-25$ years & $58(75.3)$ \\
\hline 26 years or older & $19(24.7)$ \\
\hline \multicolumn{2}{|l|}{ Marital Status } \\
\hline Single, divorced, widowed & $64(83.1)$ \\
\hline $\begin{array}{l}\text { Married or domestic } \\
\text { partnership }\end{array}$ & $12(15.6)$ \\
\hline \multicolumn{2}{|l|}{$\begin{array}{l}\text { Working at the start of the } \\
\text { pandemic }\end{array}$} \\
\hline Yes & $66(85.7)$ \\
\hline \multicolumn{2}{|l|}{$\begin{array}{l}\text { Continued work during the } \\
\text { pandemic }\end{array}$} \\
\hline Yes & $41(62.1)$ \\
\hline \multicolumn{2}{|l|}{$\begin{array}{l}\text { Changes in work after start of } \\
\text { pandemic }\end{array}$} \\
\hline Laid off & $5(7.6)$ \\
\hline Furloughed & $26(39.4)$ \\
\hline Responsibilities changed & $12(18.2)$ \\
\hline No changes & $23(34.8)$ \\
\hline \multicolumn{2}{|l|}{$\begin{array}{l}\text { Provided care to a patient with } \\
\text { known or suspected SARS-CoV-2 }\end{array}$} \\
\hline Yes & $23(29.9)$ \\
\hline \multicolumn{2}{|l|}{$\begin{array}{l}\text { Daily time spent consuming } \\
\text { media }\end{array}$} \\
\hline$<1$ hour & $26(33.8)$ \\
\hline 1-3 hours & $35(45.5)$ \\
\hline $4+$ hours & $16(20.8)$ \\
\hline \multicolumn{2}{|l|}{ Primary news source } \\
\hline Television news & $11(14.3)$ \\
\hline $\begin{array}{l}\text { Online or traditional } \\
\text { newspaper }\end{array}$ & $19(24.7)$ \\
\hline Social media & $44(57.1)$ \\
\hline Other & $3(3.9)$ \\
\hline \multicolumn{2}{|l|}{$\begin{array}{l}\text { Unable to participate in a hobby } \\
\text { due to mandatory closures }\end{array}$} \\
\hline Yes & $51(66.2)$ \\
\hline \multicolumn{2}{|l|}{$\begin{array}{l}\text { Hobby participation during } \\
\text { COVID-19 pandemic }\end{array}$} \\
\hline Yes, a new hobby & $37(48.1)$ \\
\hline Yes, an old hobby & $61(79.2)$ \\
\hline No & $8(10.4)$ \\
\hline
\end{tabular}

Participants reported having felt anxious (mean=3.99) at higher rates on average than fear $($ mean $=3.22)$, sadness $($ mean $=3.60)$, and anger $($ mean $=3.45)($ Table 2$)$. Those who were 25 years of age or younger were more likely to feel anger compared to older students, mean 3.89 versus 3.31 respectively $(\mathrm{p}=0.038)$. Students who continued to work during the pandemic were less likely to feel fear, mean 2.98 versus $3.68(\mathrm{p}=0.020)$ and sadness, mean 3.29 versus $3.96(\mathrm{p}=0.025)$. However, student pharmacists who provided care to a patient with known or suspected SARS-CoV-2 infection were significantly more likely to have felt fear than those who did not, mean 3.61 versus 3.06 respectively $(\mathrm{p}=0.034)$.

Table 2 (next page) provides mean values of emotional responses and coping strategies broken down by media use, working status, and hobby participation. Daily media use of one hour or less was compared to one to three hours and four or more hours. Participants who consumed less than one hour of media a day reported having felt less fear than those consuming one to three hours per day, mean 2.73 versus 3.49 respectively $(\mathrm{p}=0.043)$. There were no differences in reported emotional responses related to participants' primary source of news (television, print, online, or social media). Student pharmacists who participated in hobbies were significantly less likely to feel sadness compared to those who did not, mean 3.51 versus 4.80 respectively $(\mathrm{p}=0.001)$. Only two students reported plans to discontinue the hobbies they started. Nearly half (47.6\%) of students in the class of 2021 reported a reduction in hobby participation after starting Advanced Pharmacy Practice Experiences (APPE).

Approach coping strategies such as acceptance, self-distraction, positive reframing, and active coping ( mean=29.61) were used on average more frequently than avoidant coping strategies (mean=22.03) (Table 2). Behavioral disengagement, substance use, and denial were the least frequently reported coping strategies.

\section{DISCUSSION}

This study is the first to identify student pharmacist coping mechanisms and adverse emotional responses precipitated by the COVID-19 pandemic. Results confirm those of Abraham et al, in that the lives of student pharmacists have been impacted by SARS-CoV-2 [18]. Student pharmacists expressed feeling anxious, fear, sadness, and anger related to the COVID-19 pandemic. Our results are similar to reports of the psychological impact of SARS-CoV-2 outbreak on nurses and nursing students in China. Both groups also showed heightened adverse emotional reactions including anxiety, fear, anger, and sadness [4]. This is especially concerning in students who are young adults, as this population reports being disproportionately affected by mental health conditions during the COVID-19 pandemic, including anxiety disorders, depressive disorders, COVID-19 related trauma and stress related disorders, substance use to cope with pandemic-related stress or emotions, and/or suicidal behaviors [3]. 
Table 2: Feelings and Coping Strategies of Student Pharmacists During the COVID-19 Pandemic (N=77)

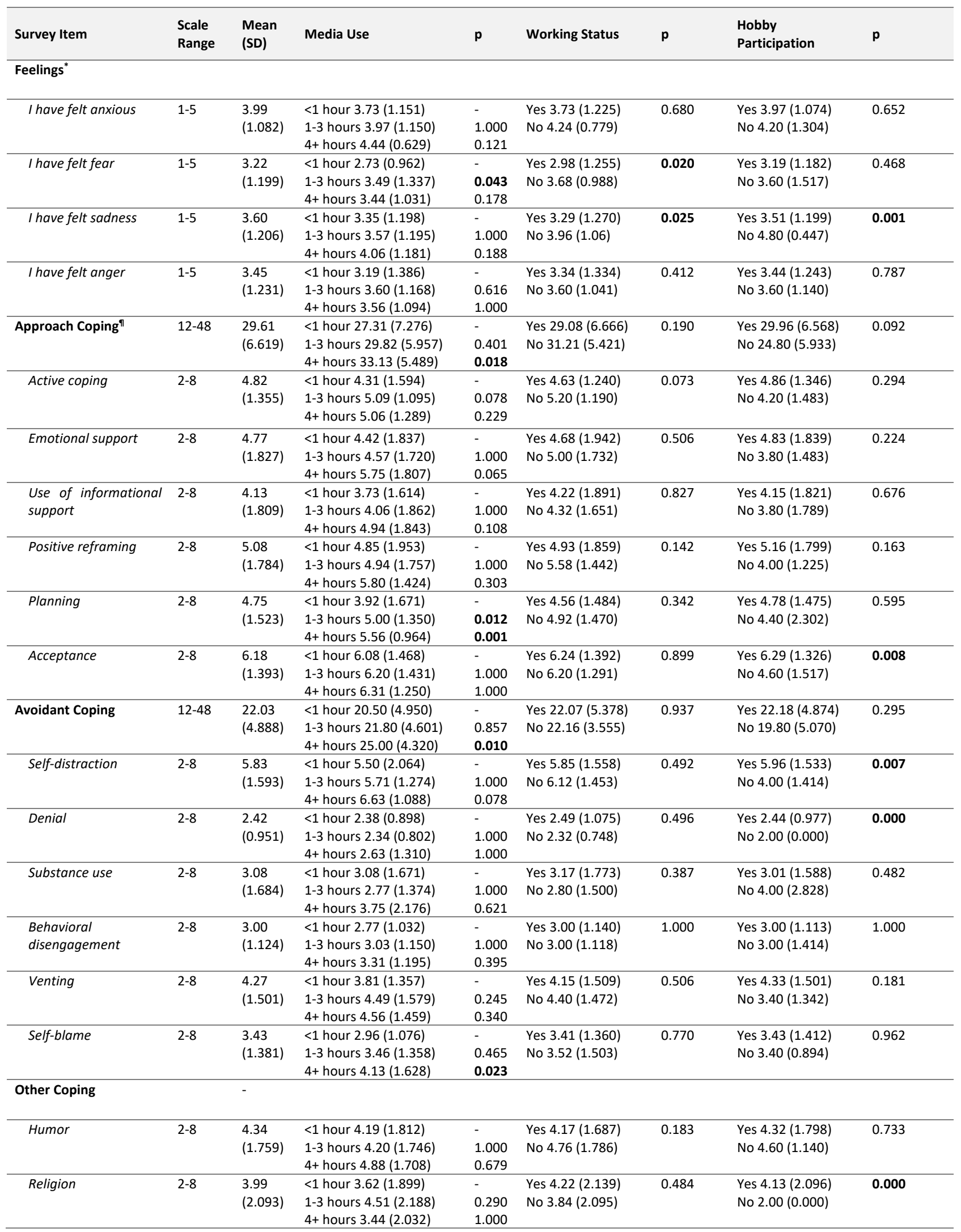

*Evaluated with a 5-point Likert scale ranging from 1 (strongly disagree) to 5 (strongly agree), with 3 (neither agree nor disagree) representing a neutral value

" Evaluated with a 4-point Likert scale from 1 (I haven't been doing this at all) to 4 (I've been doing this a lot). Each reaction was assessed twice with higher scores indicating greater use of the coping reaction by participants (maximum score $=8$ ). The score for each coping subscale (approach and avoidant) was calculated by adding the total score for each reaction within its respective subscale. 


\section{Media Consumption}

One aspect of this study was to determine how media consumption factored into responses to the pandemic. People look to media for sources of information; however, constantly streaming and sensationalized news have been shown to add to feelings of anxiety, fear, and stress [21,22]. Since the start of the pandemic, substantial increases in social media use have been seen in the adolescent population, with greater time on social media related to higher depressive symptoms [15]. The source of media did not impact negative emotional responses in this study. However, participants who spent less time consuming news-related media reported having significantly less fear; and the greatest media consumption in this study was indeed social media. It is possible that 'stressed' participants would have a difficult time differentiating any varying effects of media sources (i.e., which sources carry the greatest negative provocatory influence), and would rather only be able to report on the cumulative effect, precipitating in their stress levels. In this study it was clear: more media influence, the greater the negative stress; and the most frequently consumed source: social media. These results support calls for measures to encourage mindful consumption of media in health professions students and access to reliable, clear resources.

\section{Employment Status}

Interestingly, student pharmacists who continued to work during the COVID-19 pandemic reported having felt significantly less fear and sadness than those who did not work. It is unclear if there are aspects of work that alleviate fear and sadness or if the loss of jobs exacerbates the problem. However, these results align with others showing that job loss and unemployment have negative effects on mental and physical health [23]. Working provides an opportunity for interpersonal communication, as well as financial security for these individuals, which may explain these results. Conversely and not surprisingly, student pharmacists who provided care to a patient with known or suspected SARS-CoV-2 infection reported stronger feelings of fear. Pharmacists and student pharmacists were met with challenges of obtaining personal protective equipment (PPE) and social distancing while at the workplace [24]. Prior to the pandemic students reported multiple sources of stress; during the pandemic these stressors were compounded with feelings of fear. This compounding effect increased a need for support that could potentially be filled through discussions of healthy coping strategies.

\section{Hobby Participation}

We predicted and found that student pharmacists who participated in hobbies reported significantly less feelings of sadness. Participation in hobbies and other leisure activities is an opportunity to take a break, restore, or relax during daily life, particularly during stressful times [14]. Perspectives of student pharmacists as reported in the literature reflect the importance of maintaining self-care and social connectedness during pharmacy school to support well-being. Health professions students report that time spent in class, workload, and the obligations and demands of school leave little time or energy for pursuit of hobbies $[25,26]$. These results point to the need for health professions schools to continually monitor the delicate balance between curriculum rigor and reasonable student workload. Students need time to find and participate in hobbies they enjoy or other socially connected activities, which may help improve mood during times of stress and uncertainty.

\section{Coping Strategies}

Strategies to cope with stressors are either adaptive or problematic [27]. In this study, participants reported using approach coping more often than avoidant coping. Approach coping strategies are typically more beneficial, and likewise, developing approach coping skills will help health professions and pharmacy students navigate future stressful events. This type of skills training should be included in well-being initiatives regardless of the presence of a pandemic.

\section{LIMITATIONS}

The study represents only a small cohort of pharmacy students from a single institution, which may limit generalizability. Student pharmacists' feelings and coping strategies may vary based on geographical area and the impact the pandemic had on the area. The sample size was small with a limited response rate and there could be a sampling bias with students who were more acutely aware of the stresses of SARS-CoV-2 completing the study. Additionally, this survey was sent at the end of the initial state-mandated quarantine and represents 2 months of the COVID-19 pandemic. Students' responses were based on recall of the previous two months and may have been more positively impacted by the enthusiasm of the re-opening of some businesses.

\section{CONCLUSION}

This study is the first to assess coping strategies of student pharmacists, as well as the impact of news media consumption on negative emotional responses to a major life stressor. A cohort of student pharmacists expressed feelings of anxiety, fear, sadness, and anger related to the COVID-19 pandemic. Students who consumed less news media reported less fear. Participating in hobbies and working also reduced the feelings of sadness and fear, respectively, and should be encouraged to foster positive coping strategies. Providing and encouraging employment opportunities to students may positively affect emotional responses in times of crisis. Reduced amounts of news media consumption were correlated with less fear. Up-todate information and resources should be utilized to help reduce media consumption in times of crises. These results provide a foundation for which future hypothesis-driven research can be conducted to better understand coping strategies, media impact, and emotional responses to major life stressors in student pharmacists and other health professions students. Specifically, our results should be used to test whether certain coping strategies contribute to an overall well-being. Lastly, an overall effect size of hobbies, media consumption, and employment on stress levels should be further investigated. 
Abbreviations:

COVID-19 Coronavirus Disease 19

SARS-CoV-2 Severe Acute Respiratory Syndrome

Coronavirus 2

WHO World Health Organization

\section{REFERENCES}

1. Salari N, Hosseinian-Far A, Jalali R, Vaisi-Raygani A, Rasoulpoor S, Mohammadi M, et al. Prevalence of stress, anxiety, depression among the general population during the COVID-19 pandemic: a systematic review and meta-analysis [Internet]. Global Health. 2020 Jul;16(1):57. Available from: https://globalizationandhealth.biomedcentral.com/articles/10.1186/s12992-020-00589-w

2. World Health Organization. WHO Director-General's opening remarks at the media briefing on COVID-19 [Internet]. Geneva CHE; World Health Organization; 2020 [updated 2020 March 11; cited 2020 Sept 26]. Available from: https://www.who.int/dg/speeches/detail/ who-director-general-s-opening-remarks-at-the-mediabriefing-on-covid-19---11-march-2020

3. Czeisler ME, Lane RI, Petrosky E, et al. Mental Health, Substance Use, and Suicidal Ideation During the COVID-19 Pandemic - United States, June 24-30, 2020. MMWR Morb Mortal Wkly Rep 2020 [Internet]. 2020 Aug;69:1049-57. Available from: https://www.cdc.gov/mmwr/volumes/69/ wr/mm6932a1.htm?s_cid=mm6932a1_w

4. Huang L, Lei W, Xu F, Liu H, Yu L. Emotional responses and coping strategies in nurses and nursing students during Covid-19 outbreak: A comparative study [Internet]. PLoS One. 2020 Aug;15(8):e0237303. Available from: https:// emj-bmj-com.ezproxy.uky.edu/content/24/1/12.long

5. Stone JK, Pate AN. The Impact of COVID-19 Through the Eyes of a Fourth-Year Pharmacy Student [Internet]. Am J Pharm Educ. 2020 Jun;84(6):ajpe8146. Available from: https://www.ajpe.org/content/84/6/ajpe8146 https://doi. org/10.5688/ajpe8146.

6. Basheti IA, Nassar R, Barakat M, Alqudah R, Abufarha R, Mukattash TL, et al. Pharmacists' readiness to deal with the coronavirus pandemic: assessing awareness and perception of roles [Internet]. Res Social Adm Pharm. 2021 Mar;17(3):514-22.

7. Washington State University. Embedded: Student pharmacist on the frontlines of COVID-19 testing in Yakima [Internet]. Yakima County: Washington State University; 2020 [updated 2020 Jul 24; cited 2020 Sep 26]. Available from: https://pharmacy.wsu.edu/2020/07/24/ embedded-student-pharmacist-on-the-frontlines-of-covid19-testing-in-yakima/

8. Rochford C, Connolly M, Drennan J. Paid parttime employment and academic performance of undergraduate nursing students [Internet]. Nurse Educ Today. 2009 Aug;29(6):601-6. Available from: https://www.sciencedirect.com/science/article/pii/ S0260691709000161?via\%3Dihub

9. Okogbaa J, Allen RE, Sarpong DF. Time Spent at Work and Its Impact on the Academic Performance of Pharmacy Students [Internet]. Int J Environ Res Public Health. 2020 Jan;17(2):496.

10. Alalawi N, Al-Jenaibi B. A research into the fact that media have direct effects on people in different ways. J Mass Communicat Journalism [Internet]. 2016;6(287):2. Available from: https://www.hilarispublisher.com/open-access/aresearch-into-the-fact-that-media-have-direct-effects-onpeop-le-indifferent-ways-2165-7912-1000287.pdf

11. Zhao N, Zhou G. Social Media Use and Mental Health during the COVID-19 Pandemic: Moderator Role of Disaster Stressor and Mediator Role of Negative Affect [Internet]. Appl Psychol Health Well-Being. 2020 Dec;12(4):1019-38. Available from: https://iaap-journals. onlinelibrary.wiley.com/doi/epdf/10.1111/aphw.12226

12. Dhanashree GH, Chauhan A, Bhatia M, Sethi G, Chauhan G. Role of mass media and it's impact on general public during coronavirus disease 2019 pandemic in North India: an online assessment [Internet]. Indian J Med Sci. 2021;73(1):21-5. Available from: https://ijmsweb. com/role-of-mass-media-and-its-impact-on-general-public-during-coronavirus-disease-2019-pandemic-in-north-india-an-online-assessment/DOI:10.25259/ IJMS_312_2020

13. Lee JJ, Kang KA, Wang MP, Zhao SZ, Wong JY, O'Connor S, et al. Associations Between COVID-19 Misinformation Exposure and Belief With COVID-19 Knowledge and Preventive Behaviors: Cross-Sectional Online Study. J Med Internet Res. 2020 Nov;22(11):e22205.

14. Pressman SD, Matthews KA, Cohen S, Martire LM, Scheier M, Baum A, et al. Association of enjoyable leisure activities with psychological and physical well-being [Internet]. Psychosom Med. 2009 Sep;71(7):725-32. Available from: https://journals-lww-com.ezproxy. uky.edu/psychosomaticmedicine/Fulltext/2009/09000/ Association_of_Enjoyable_Leisure_Activities_With.5.aspx

15. Ellis WE, Dumas TM, Forbes LM. Physically isolated but socially connected: psychological adjustment and stress among adolescents during the initial COVID-19 crisis [Internet]. Can J Behav Sci. 2020;52(3):177-87. Available from: https://psycnet.apa.org/fulltext/2020-50562-001.html

16. Carver C. Coping. In: Gellman MD, Turner JR, editors. Encyclopedia of Behavioral Medicine. New York (NY): Springer New York; 2013. pp. 496-500., Available from https://link.springer.com/referenceworkentry/10.1007\% 2F978-1-4419-1005-9_1635

17. Carver CS. You want to measure coping but your protocol's too long: consider the brief COPE [Internet]. Int J Behav Med. 1997;4(1):92-100. Available from: https:// link-springer-com.ezproxy.uky.edu/article/10.1207/ s15327558ijbm0401_6

18. Abraham O, Babal JC, Brasel KV, Gay S, Hoernke M. Strategies first year doctor of pharmacy students use to promote well-being [Internet]. Curr Pharm Teach Learn. 2021 Jan;13(1):29-35. Available from: https://www-sciencedirect-com.ezproxy.uky.edu/science/article/pii/ S187712972030277X?via\%3Dihub

19. Yusoff N, Low WY, Yip CH. Reliability and validity of the 
Brief COPE Scale (English version) among women with breast cancer undergoing treatment of adjuvant chemotherapy: a Malaysian study [Internet]. Med J Malaysia. 2010 Mar;65(1):41-4. Available from: http://www.e-mjm. org/2010/v65n1/Brief_COPE_Scale.pdf

20. Roth S, Cohen LJ. Approach, avoidance, and coping with stress [Internet]. Am Psychol. 1986 Jul;41(7):813-9. Available from: https://psycnet-apa-org.ezproxy.uky.edu/ record/1986-27206-001?doi=1

21. Holman EA, Thompson RR, Garfin DR, Silver RC. The unfolding COVID-19 pandemic: A probability-based, nationally representative study of mental health in the United States [Internet]. Sci Adv. 2020 Oct;6(42):eabd5390. Available from: https://advances-sciencemag-org.ezproxy. uky.edu/content/6/42/eabd5390 https://doi.org/10.1126/ sciadv.abd5390.

22. Cao W, Fang Z, Hou G, Han M, Xu X, Dong J, et al. The psychological impact of the COVID-19 epidemic on college students in China [Internet]. Psychiatry Res. 2020 May;287:112934. Available from: https://www-sciencedirect-com.ezproxy.uky.edu/science/article/pii/ S0165178120305400?via\%3Dihub

23. Zhang SX, Wang Y, Rauch A, Wei F. Unprecedented disruption of lives and work: Health, distress and life satisfaction of working adults in China one month into the COVID-19 outbreak [Internet]. Psychiatry Res. 2020 Jun;288:112958. Available from: https:// www-sciencedirect-com.ezproxy.uky.edu/science/article/ pii/S0165178120306521?via\%3Dihub

24. Hasan SS, Kow CS, Zaidi ST. Social distancing and the use of PPE by community pharmacy personnel: does evidence support these measures? [Internet]. Res Social Adm Pharm. 2021 Feb;17(2):456-9. Available from: https:// www-sciencedirect-com.ezproxy.uky.edu/science/article/ pii/S1551741120304903?via\%3Dihub

25. Babal JC, Abraham O, Webber S, Watterson T, Moua P, Chen J. Student Pharmacist Perspectives on Factors That Influence Wellbeing During Pharmacy School [Internet]. Am J Pharm Educ. 2020 Sep;84(9):ajpe7831. Available from: https://www.ajpe.org/content/84/9/ajpe7831 https:// doi.org/10.5688/ajpe7831.

26. Tempski P, Bellodi PL, Paro HB, Enns SC, Martins MA, Schraiber LB. What do medical students think about their quality of life? A qualitative study [Internet]. BMC Med Educ. 2012 Nov;12(1):106. Available from: https://bmcmededuc.biomedcentral.com/ articles/10.1186/1472-6920-12-106

27. Carver CS, Scheier MF, Weintraub JK. Assessing coping strategies: a theoretically based approach [Internet]. J Pers Soc Psychol. 1989 Feb;56(2):267-83. Available from: https://doi.apa.org/doiLanding?doi=10.1037\% 2F0022-3514.56.2.267 